\title{
The control to aggregates of pumping stations using a regulator based on a neural network with fuzzy logic
}

\author{
Vladlen Kuznetsov ${ }^{1}$, Sergey Dyadun ${ }^{2,3 *}$, and Valentin Esilevsky ${ }^{4}$ \\ ${ }^{1}$ Starooskolsky Technological Institute of the Moscow Institute of Steel and Alloys, \\ 42 Makarenko District, Stary Oskol, Belgorod region, Russia \\ ${ }^{2}$ O.M. Beketov National University of Urban Economy in Kharkov, \\ 17, Marshala Bazhanova str., Kharkov, 61002, Ukraine \\ ${ }^{3}$ Karazin National University in Kharkov, 6, Svobody Square, Ukraine \\ ${ }^{4}$ National University of Radio Electronics in Kharkov, 14, Nauki Avenue, Ukraine
}

\begin{abstract}
A pumping station control system is considered using a controller based on a fuzzy logic neural network. The simulation of the classical and fuzzy regulators. The possibility of the implementation of the controller in the form of an adaptive multilayer neural network is shown. The use of the theory of fuzzy sets in combination with the theory of neural networks to create a fuzzy-neural regulator to control pumping units provides a promising approach. Simulation modeling and real operation have shown that fuzzy-logic regulators have a number of advantages over classical regulators, which allow the use of form and limitations. Using the neural network model allows you to add the properties of adaptability and learning. The fuzzy-neural controller for controlling pumping units is promising in terms of efficiency and safety by controlling pumping stations.
\end{abstract}

\section{Introduction}

When pumping wastewater, the correct determination of the capacity of tanks and pumping units is of great importance. It is unacceptable to use too large tanks, as well as to allow longterm stagnation of water in the tank. In the case of a small tank capacity, the operation of the pumping station is significantly complicated due to the large number of switching on of the pumping units. The greater the power of the electric motor of the pump unit, the less of its inclusions are allowed for a certain time [1].

The automation of most sewage pumping stations works according to the following principle. Upon reaching a certain level in the storage tank include one pump unit; if the water level in the tank continues to increase and reaches another mark, then another pump unit is activated, and so on. After a certain time, when the water from the tank is pumped out completely, the pumping units are turned off. Such a system leads to inefficient use of electricity, and in certain situations, excessively frequent switching on or too long operation of pumping units, as well as the stagnation of water in the tank.

\section{Formulation of the problem}

\footnotetext{
*Corresponding author: daulding@mail.ru
} 
Consider a model of a sewage pumping station with a receiving tank and the maximum allowable water level in it $h_{\max }$. Denote: $J$ - many pressure pipelines; $I_{j \max }, j \in J$ - many identical in characteristics available for the inclusion of pumping units on the $\mathrm{j}$-th pressure pipe; $Q_{n p}(t), t \in G$ - the volume of water entering the storage tank.

It is necessary to draw up such a schedule for starting pumping units $\mathrm{I}_{\mathrm{j}}(\mathrm{t})$, and $I_{j}(t) \epsilon I_{\max }$, $j \in J, t \epsilon T$, to minimize the total energy consumption for all pumping units

$$
N_{\text {oб̆u }}=\sum_{t}^{\mathrm{T}} \sum_{j}^{\mathrm{J}} \sum_{i}^{I_{j}(t)} N_{\mathrm{ij}}\left(Q_{j}\right)
$$

under restrictions:

- time of stagnation of water in the tank should not exceed the maximum permissible rate: $t_{3 a m}<t_{3 a c m \text { max }}$

- the number of inclusions of pumping units for a certain period of time should not exceed the maximum allowable $I_{j}(t)<I_{\max }$.

\section{System operation simulation}

The proposed solution is based on the theory of fuzzy sets and mappings. In this paper, the fuzzy control algorithm is implemented for a pump sewage station with an average daily capacity $22000 \mathrm{~m}^{3}$, receiving tank $4 \mathrm{~m} * 1 \mathrm{~m} * 10 \mathrm{~m}$, volume $40 \mathrm{~m}^{3}$. From the station laid two pressure pipe. There are 4 F-type pumping units installed at the station, two for each pressure pipe, with $540 \mathrm{~m}^{3} / \mathrm{h}$ and head $94 \mathrm{~m}$. A graphic representation of the model of the pumping station is shown in Fig. 1, where 1 - pumping units, 2 - receiving tank, 3 - pressure pipelines. The model of the station was built on the basis of a real sewage pumping station (SPS No. 15a - Yuzhkabel, Kharkov).

The system was simulated for a period of 24 hours (day). A forecast of the inflow of

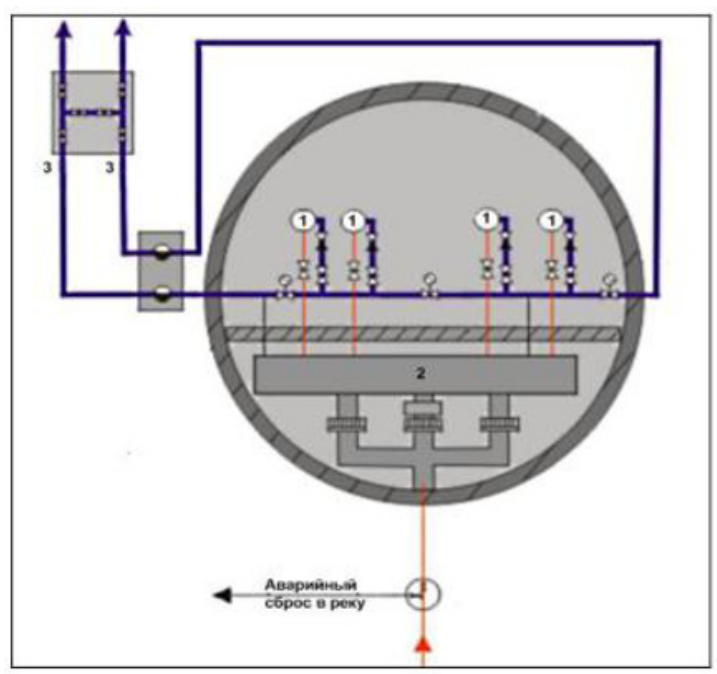

Fig. 1. Graphic representation of sewage pumping station sewage into the receiving tank of the sewage station under consideration was compiled, depending on the time of day, the graph of which is shown in Fig. 2. For comparison, the classical control system at pumping stations was selected, in which the switching on of pumping units took place at levels of $3 \mathrm{~m}, 3.3 \mathrm{~m}, 3.6 \mathrm{~m}, 3.7 \mathrm{~m}$ of storage tank.

As a result of the simulation, graphs of changes in the water level versus time of day were obtained for the classical control system (Fig. 3a) and the fuzzy controller (Fig. 3b), as well as graphs of the number of running pumps for the classical control system (Fig. 4a) and the fuzzy controller (Fig. 4b). As can be seen from the graphs of the classical system, during hours of a change in water flow, situations may arise when the time of stagnation of water in the tank and the time of continuous operation of pumping units is too large, or vice versa - the frequency of pump unit starts in certain situations becomes too large, which 
negatively affects power equipment.

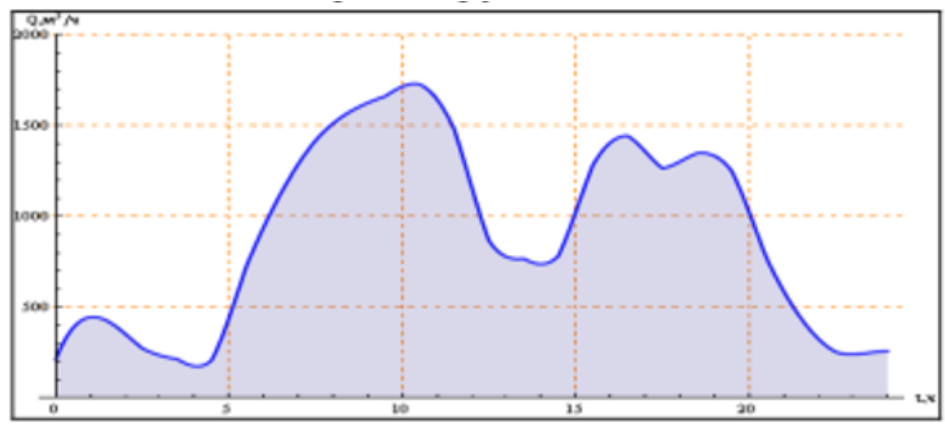

Fig. 2. Graph of the real flow of wastewater into the receiving tank, depending on the time of day

$a$

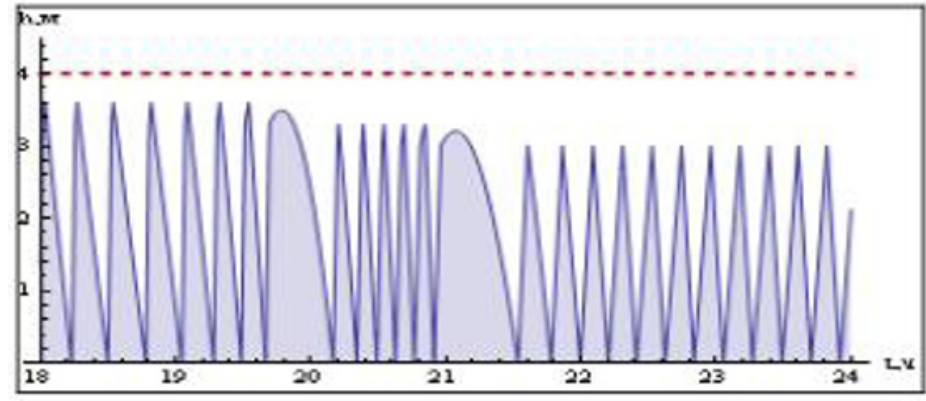

$b$

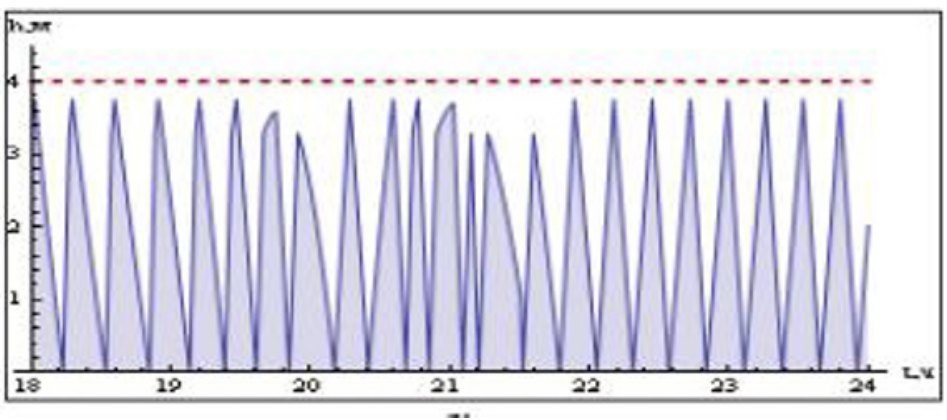

Fig. 3. Schedule of changes in the water level over a period of time from 18.00 to 0.00 for a) the classical control system, b) a fuzzy controller

As can be seen from the above data and comparative data in the table, the developed algorithm of the fuzzy controller has several advantages over the classical control scheme used in sewage pumping stations. And although the difference in energy costs is not great, nevertheless, it was possible to achieve improvements in most of the other criteria under consideration, which will positively affect the condition of the equipment of the pumping station, and as a result, the costs for its maintenance and repair will decrease. 
Table 1. Comparison of a classical control system and a fuzzy regulator

\begin{tabular}{|c|c|c|}
\hline Maximum time of stagnation of water in the tank, min & 84 & 25 \\
\hline Comparative criterion & $\begin{array}{c}\text { Classic } \\
\text { system } \\
\text { of management }\end{array}$ & $\begin{array}{c}\text { Fuzzy } \\
\text { regulator }\end{array}$ \\
\hline Total electricity consumed, $\mathrm{kW}$ & 10444,5 & 10389,5 \\
\hline The average time of stagnation of water in the tank, min & 15 & 16 \\
\hline The total number of starts of pumping units & 203 & 215 \\
\hline The total operating time of all pumping units & $23 \mathrm{~h} \mathrm{55min}$ & $22 \mathrm{~h} \mathrm{40min}$ \\
\hline Maximum time of one pump unit operation without stopping, min & 84 & 25 \\
\hline
\end{tabular}

\section{Construction of neural network implementation of fuzzy regulation}

The disadvantage of the fuzzy control system is the impossibility of automatic adaptation and training. To solve this problem, we use the approach based on neural networks. Imagine a fuzzy control system in the form of a multilayer network with direct signal propagation. For their learning, it is customary to use an error propagation algorithm. This will allow to realize a fuzzy control module in the form of a multilayered neural network, which will have adaptability.

$a$

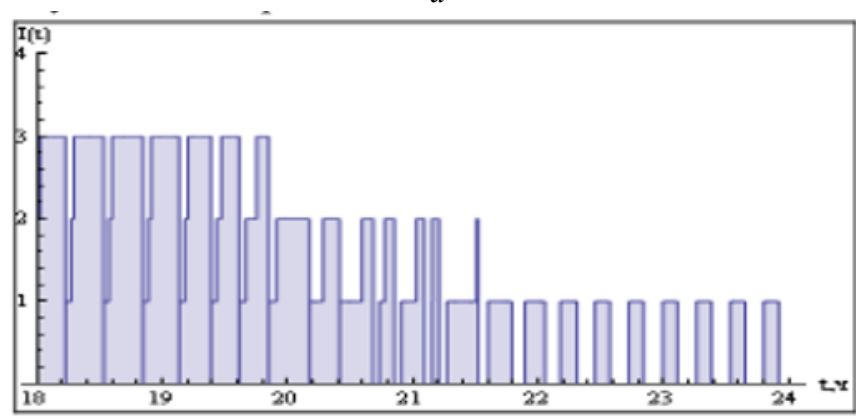

$\sigma$

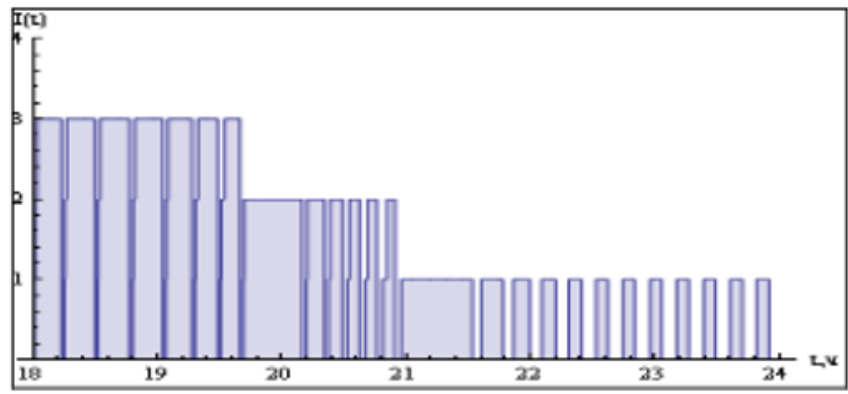

Fig. 4. A graph of the number of included pumps for the period from 18.00 to 0.00 at a) classical control system, b) fuzzy controller

A control system based on fuzzy sets can be brought to a form suitable for neural network modeling [2]. To do this, it is necessary to present a fuzzy set of functions in the form of a dome-shaped Gauss function. In this case, its two parameters (center and width) can be adjusted in the learning process. The operation of fuzzy implication can be represented as a 
product, which can also be easily simulated as the propagation of a signal in a network. This type of system is one of the frequently used methods for implementing fuzzy systems. Each element of such a system can be defined in the form of a functional block (sum, product, Gauss function), which allows you to create a multilayer network presented in Fig. 5. Layers are labeled L1 to L4. In the presented network there are several layers.

Layer 1 (L1). Each element implements the membership function of a fuzzy set. Input signals enter this layer, and the values of the membership function for these signals are generated at its output. The functional relationship between the input and output at the nodes of this layer is determined by the Gauss function. Its parameters will be modified in the learning process, which will improve the selection of fuzzy sets. The number of elements of the L1 layer is determined by the number of input elements and rules and is equal to the product of the number of input variables and fuzzy rules.

Layer 2 (L2). The configuration of the links of this layer corresponds to the rule base, and the multipliers to the output block. The output of the L2 layer is the result of output in the form of the membership function value. The number of elements of this layer is equal to the number of rules $\mathrm{N}$. The use of multipliers as nodes of the L2 layer is due to the fact that the multiplication operation is used for fuzzy implication.

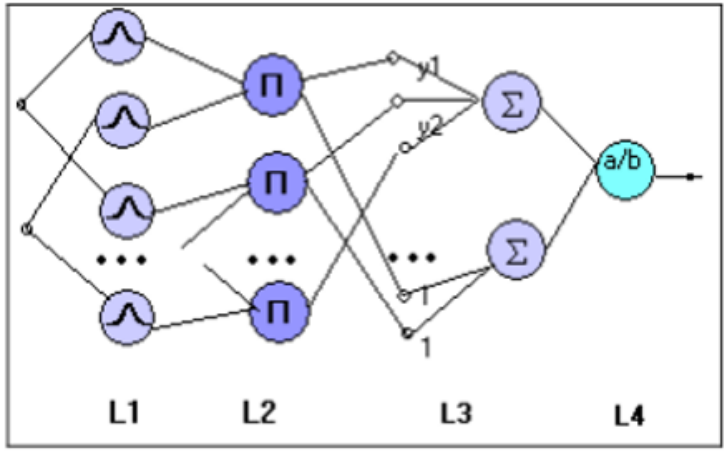

Fig. 5. Scheme of the neural network implementation of the fuzzy control module

Layer 3 (L3) and (E4). Both layers represent the implementation of the defuzzing unit. The weights of connections reaching the upper layer L3 and denoted by yi are interpreted as centers of the membership functions of fuzzy sets. These weights will be modified in the learning process. At the output of the L4 layer system, a "clear" (defuzzified) output value of the control module y is formed. The resulting circuit is a multilayer network based on fuzzy inference. Therefore, it can be trained in the same way as a normal neural network, if we use the generalized back-propagation error algorithm [2]. For this, a training sample in the form of pairs is needed: the input vector is a reference output signal that can be obtained by observing the actual operation of the pumping station.

\section{Conclusions}

The use of the theory of fuzzy sets in combination with the theory of neural networks to build a fuzzyneural regulator to control pumping units of wastewater confirms the promise of this approach. Simulation modeling and real operation showed that a controller based on fuzzy logic has several advantages over classical regulators, allowing one to take into account difficultly formalized restrictions and rules. The use of the neural network model in the design of the fuzzy regulation system allows you to add the properties of adaptability and learning.

The fuzzy neural regulator for controlling pumping units is a promising method for controlling pumping stations in terms of efficiency and safety. 


\section{References}

1. A.G. Evdokimov, A.D. Tevyashev, V.V. Dubrovsky Modeling and optimization of flow distribution in engineering networks (Stroyizdat, Moscow, 1990)

2. V.M. Turk, A.V. Minaev, V.K. Karelin, Pumps and pumping stations (Stroyizdat, Moscow, 1990)

3. V.S. Esilevsky, V.N. Kuznetsov, L.V. Uvarova, Plumbing. Water supply, 1, 64 (2009)

4. S.V. Dyadun, Utilities of cities, 1, 63 (1992)

5. S.V. Dyadun, Radio electronics and computer science, 16, 46 (2001)

6. I. Pulido-Calvo, Environmental Research Journal, 5 (1), 1 (2011)

7. D, Rutkovskaya, M. Pilinsky, L. Rutkovsky, Neural networks, genetic algorithms and fuzzy systems: Trans. from polish (Hotline, Telecom, 2004)

8. G. D'Emilia, A. Marrab, E. Natalea, Robotics and Computer-Integrated Manufacturing, 23, 170 (2007)

9. S. Omatu, M. Khalid, R. Yusof, Neuro-management and its applications: Per. from English (IPRZHR, Moscow, 2000)

10. M.T. Hagan, H.B. Demuth, Proceedings of the American Control Conference, 3, 1642 (1999)

11. V.I. Arkhangelsky, I.N. Bogayenko, G.G. Grabovsky, N.A. Ryumshin, Neural networks in automation systems (Technique, Kiev, 1999)

12. O. Omidvar, D.L. Elliott eds, Neural Systems for Control (Academic Press, New York, 1997)

13. Shigeru Omatu, Neuromanagement and its applications (IPRZHR, Moscow, 2000)

14. S. Khaikin, Neural networks: a full course (Williams, Moscow, 2006)

15. G. G. Lendaris, Proceedings of International Joint Conference on Neural Networks, 1750 (Atlanta, USA, 2009)

16. K. Krishnakumar, G. Limes, K. Gundy-Burlet, D. Bryant, Proceedings of 2003 AIAA Guidance, Navigation, and Control Conference, 5790 (Austin, USA)

17. G. Tchobanoglous, F. Burton, H. Stensel, Wastewater Engineering: Treatment and Reuse (New York, McGraw-Hill, 2003)

18. W.D. Chang, R.C. Hwang, J.G. Hsiehc, Engineering Applications of Artificial Intelligence, 16(1), 57 (2003)

19. A.Rincón, J. Villa, F. Angulo, G. Olivar, Mathematical Problems in Engineering (2014)

20. T. Hope, Y. Resheff, and I. Lieder, Learning TensorFlow (O'Reilly, 2017) 